\title{
Are health care professionals able to judge cancer patients' health care preferences correctly? A cross-sectional study
}

\author{
Hester Wessels 1,2, Alexander de Graeff2, Klaske Wynia33, Miriam de Heus'1, Cas LJJ Kruitwagen4, Saskia CCM Teunissen² \\ and Emile E Voest ${ }^{* 2}$
}

\begin{abstract}
Background: Health care for cancer patients is primarily shaped by health care professionals. This raises the question to what extent health care professionals are aware of patients' preferences, needs and values.

The aim of this study was to explore to what extent there is concordance between patients' preferences in cancer care and patients' preferences as estimated by health care professionals. We also examined whether there were gender differences between health care professionals with regard to the degree in which they can estimate patients' preferences correctly.
\end{abstract}

Methods: To obtain unbiased insight into the specific preferences of cancer patients, we developed the 'Cancer patients' health care preferences' questionnaire.' With this questionnaire we assessed a large sample of cancer patients $(n=386)$. Next, we asked health care professionals (medical oncologists, nurses and policymakers, $n=60$ ) to fill out this questionnaire and to indicate preferences they thought cancer patients would have. Mean scores between groups were compared using Mann-Whitney tests. Effect sizes (ESs) were calculated for statistically significant differences.

Results: We found significant differences (ESs 0.31 to 0.90) between patients and professionals for eight out of twentyone scales and two out of eight single items. Patients valued care aspects related to expertise and attitude of health care providers and accessibility of services as more important than the professionals thought they would do. Health care professionals overestimated the value that patients set on particularly organisational and environmental aspects. We found significant gender-related differences between the professionals (ESs 0.69 to 1.39) for eight out of twentyone scales and two out of eight single items. When there were significant differences between male and female healthcare professionals in their estimation of patients health care preferences, female health care professionals invariably had higher scores. Generally, female health care professionals did not estimate patients' preferences and needs better than their male colleagues.

Conclusions: Health care professionals are reasonably well able to make a correct estimation of patients preferences, but they should be aware of their own bias and use additional resources to gain a better understanding of patients' specific preferences for each patient is different and ultimately the care needs and preferences will also be unique to the person.

\section{Background}

Health care providers search for solutions to deliver patient centered care that is respectful of and responsive

* Correspondence: E.E.Voest@umcutrecht.nl

2 Department of Medical Oncology, University Medical Center Utrecht, Heidelberglaan 100, 3508 GA, Utrecht, The Netherlands

Full list of author information is available at the end of the article to individual patient preferences, needs and values. Although patient advocacy groups have increasing influence on health care organizations, health care is mostly shaped by health care professionals. An important condition for health care professionals to provide optimal patient centered care, is a good insight into the patients' needs and preferences concerning health care $[1,2]$. 
To obtain insight in the specific preferences of cancer patients, we have developed the 'Cancer patients' health care preferences' questionnaire', based on patients' unrestricted input [3]. This questionnaire is not a satisfaction questionnaire, but a questionnaire that evaluates the importance of care aspects. The questionnaire was given to a large sample of patients treated by medical oncologists. In a previous study [3], it appeared that patients set highest value on safety and on the expertise, attitude and communicative skills of doctors and nurses. Of relatively less importance are the organisational and environmental factors.

Patients with cancer may encounter physical, existential and emotional problems. Information about cancer patients' needs and preferences can, to some extent, be derived from the literature [4-14]. Still, tailoring care as much as possible to the patients' needs and preferences will especially be based on the insight of the individual health care professional. This raises the question to what degree health care professionals are able to estimate patients' needs and preferences correctly.

Previous research examining the estimation of patient needs by health care professionals focuses on the impact of cancer and the side effects of chemotherapy [15], psychological concerns and needs [16,17] and patient reported physical and psychosocial problems $[18,19]$. These studies show that there is a considerable discrepancy on various issues between patients' and health care professionals' perceptions. Lack of concordance between patients and health care providers may result in less than optimal health care. In relation to these findings Brennan et al. [20] state that if nurses, physicians and health care planners knew more about patients' health-related preferences, care would most likely be cheaper, more effective and closer to the individuals' desires.

To our knowledge, the question of whether health care professionals estimate cancer patients' preferences for health care (in general) correctly, has not been studied systematically. Therefore, the aim of the present study was to examine to what extent there is concordance between cancer patients' preferences for health care, and the estimation of patient preferences by health care professionals.

In a previous study we found significant differences between male and female patients concerning their preferences in health care [21]. As gender differences with regard to communication style, practice style and relationship with patients were also found for health care professionals [22-25] we decided to examine additionally whether there are gender differences between health care professionals with regard to the degree in which they can estimate patients' preferences correctly.

\section{Methods}

\section{Questionnaire and patients}

The research protocol was approved by the Medical Ethics Commission of the University Medical Center Utrecht.

The development of the 'Cancer patients' health care preferences' questionnaire' has been described elsewhere [3]. Briefly, items concerning preferences for health care were generated during focus group interviews with cancer patients. Patients for the focus group interviews were recruited by medical oncologists of the University Medical Center Utrecht and through the Dutch Federation of Cancer Patient Organisations. Eligible patients had a sufficient physical condition to participate in the interview and were able to speak and understand the Dutch language. Finally 51 patients participated. Patient characteristics were: $67 \%$ female, $39 \%<35$ year, main tumour types were breast (18\%), urological (20\%), genital $(10 \%)$ and gastrointestinal (6\%). During the two hours lasting focus groups only one question was put forward by the panel leader: 'How would you design health care if you were in charge?' Participants were explicitly asked to think out of the box and forget potential constraints. Each interview was digitally recorded and transcribed. Text fragments were independently coded and categorized by two authors (HW, MdH). Based on analysis diagrams questions were formulated by two researchers and a questionnaire containing 136 items was generated. Each item evaluates the level of importance on a 4-point scale, ranging from 'Not important' (1), 'Somewhat important' (2), 'Important' (3), to 'Extremely important' (4).

The questionnaire was distributed among patients in care of medical oncologists from one university medical center and six community hospitals in the region of Utrecht, the Netherlands. Doctors and nurses of these departments handed out the questionnaires to an unselected sample of consecutive cancer patients. The questionnaires were encoded by hospital. A cover letter informed patients about the aim of the study and the importance of their input. Respondents were assured that their answers would be kept confidential and that the data would be processed anonymously. A phone number and email-address to contact the project manager were provided. Respondents could complete the questionnaire at home and send it back anonymously in a self addressed pre-stamped envelope. A reminder was sent to each patient after four weeks. The Medical Research Ethics Committee judged that it was not necessary for patients to sign a consent form for the study.

An explorative factor analysis with Varimax rotation was performed, resulting in the final questionnaire containing 21 scales with 115 items and 8 single items. Internal consistency of the scales was sufficient to good. The 
process of deleting and including items into scales is described elsewhere [3].

All scores of scales and single items are transformed to a score of $0-100$, with high values indicating a high level of importance.

\section{Health care professionals}

Health care professionals involved in the delivery and organisation of care for cancer patients (doctors and nurses of the departments of medical oncology and members of hospital management) of the seven participating hospitals were asked to participate in the study and to fill out the 'Cancer patients' health care preferences' questionnaire' [3]. Per participating hospital questionnaires were handed to a contact person who distributed the questionnaires to the health care professionals. We asked respondents to indicate health care preferences they thought cancer patients would have. Questions regarding respondents' gender, age and discipline were added. A cover letter informed participants about the aim of the study and the importance of their input. Respondents returned the questionnaire anonymously. A reminder was sent to each health care professional after three weeks.

\section{Data analyses}

Data were analysed using SPSS version 15.0 (SPSS Inc., Chicago, IL). Mean scores between groups were compared using Mann-Whitney tests. In case of significant differences $(p<.05)$ between groups, effect sizes $(E S s)$ were calculated to estimate the magnitude of these differences. According to Cohen's thresholds [26], an effect size of $<0.20$ indicates a trivial effect, an ES of $\geq 0.20$ to $<0.50$ a small effect, an ES of $\geq 0.50$ to $<0.80$ a moderate effect and an ES of $\geq 0.80$ a large effect. An ES $\geq 0.20$ reflects a relevant difference between groups [27].

\section{Results}

\section{Patients and health care professionals}

Between October 2006 and March 2007, 681 questionnaires were handed out to patients. In total 386 questionnaires were returned (57\% response rate) and included in the analysis. Characteristics (based on self-report) of these patients are summarized in Table 1.

Between May and August 2007, 165 questionnaires were distributed to health care professionals. Sixty questionnaires were returned (36\% response rate) and included in the analysis. Characteristics of the health care professionals are provided in Table 1.

\section{Comparison of results of patients and health care professionals}

Table 2 shows the results of the scales and single items (ranked in level of importance according to the mean scores as indicated by the patients) for both health care professionals and patients. Overall there is a strong corre- lation between both groups (Spearman correlation coefficient 0.92).

However, for 8 of the 21 scales and 2 of the 8 single items, we found statistically significant differences between health care professionals and patients. All effect sizes of these scales and single items were between 0.31 and 0.44 with the exception of the single item concerning the quality of hospital equipment, which had a very strong effect size (0.90).

Of these ten scales and single items, patients rated five scales and single items as more important than health care professionals expected: 'Physician and nurse expertise' (items concerning knowledge and experience, complete information about the patients situation and specialisation in cancer care), 'Physician attitude' (items concerning friendliness, time, personal attention, respect, empathy, attention to the patients loved ones, accuracy, opportunity for the patient to ask questions and trust), 'Accessibility of services' (e.g. access to all professionals involved in various situations), 'Hospital equipment' ('The hospital equipment is modern') and 'Consultation at the emergency room by own doctor'. The largest (18 points) and strongest (ES 0.90) difference between the estimation of health care professionals and patients was found for the single item 'Hospital equipment'. Patients valued modern hospital equipment much higher than health care professionals expected the patients to do.

Patients rated five scales less important than health care professionals expected: 'Support, counseling and rehabilitation' (offering professional support to help patients and their loved ones to deal with emotions and to help patients to re-integrate into their previous daily routine (home, work, school, etc), attention for late effects of treatment)', 'Privacy' (both at the outpatient clinic and on the ward), 'Patient habits', (items concerning individual preferences and requirements, decoration of the room, dietary habits and requirements), 'Patient interest groups' and 'Conveniences' (items concerning the waiting room and the patients room, access to sport and recreation facilities, availability of tea, coffee, soft drinks and soup).

\section{Comparison of male and female health care professionals}

We found gender-related differences within the health care professionals for eight scales and two single items (effect sizes between 0.69 and 1.39) (Table 3). When there were clinically relevant differences, female health care professionals invariably had higher scores. We found the same pattern of gender differences for patients in a previous study [21]. Female patients valued a substantial part of the aspects of care as more important than their male counterparts (Table 3). However, gender differences for patients were much more pronounced and partly for different scales and single items compared to the differences between male and female health care professionals. 
Table 1: Characteristics of patients and health care professionals

\begin{tabular}{|c|c|c|}
\hline Characteristic & $\begin{array}{l}\text { Patients } \\
(n=386) \\
\text { Percent }\end{array}$ & $\begin{array}{l}\text { Health care professionals } \\
(\mathrm{n}=60) \\
\text { Percent }\end{array}$ \\
\hline \multicolumn{3}{|l|}{ Hospital } \\
\hline University Medical Center & 27 & 35 \\
\hline Affiliated hospital & 73 & 65 \\
\hline \multicolumn{3}{|l|}{ Sex } \\
\hline Male & 35 & 20 \\
\hline Female & 66 & 78 \\
\hline Unknown & - & 2 \\
\hline \multicolumn{3}{|l|}{ Age, years } \\
\hline $18-35$ years & 5 & 32 \\
\hline $36-50$ years & 28 & 53 \\
\hline $51-65$ years & 38 & 12 \\
\hline $66-79$ years & 26 & - \\
\hline Unknown & 4 & 2 \\
\hline Level of education & & NA \\
\hline Less than high school & 9 & . \\
\hline High school & 62 & . \\
\hline More than high school & 30 & . \\
\hline Discipline & NR & \\
\hline Physician & . & 13 \\
\hline Nurse & . & 67 \\
\hline Policymaker & . & 10 \\
\hline Unknown & . & 10 \\
\hline Type of cancer patients were treated for & & NR \\
\hline Gastrointestinal & 21 & . \\
\hline Breast & 45 & . \\
\hline Skin & 1 & . \\
\hline Urological & 10 & . \\
\hline Genital & 10 & . \\
\hline Head and neck & 2 & . \\
\hline Lung & 1 & . \\
\hline Other & 12 & . \\
\hline Type of treatment (concurrent or previous)* & & NR \\
\hline Chemotherapy & 78 & . \\
\hline Hormonal therapy & 26 & . \\
\hline Experimental treatment & 4 & . \\
\hline Radiation therapy & 46 & . \\
\hline Chemo radiation & 3 & . \\
\hline Surgery & 72 & . \\
\hline Other & NA & . \\
\hline Stage & & NR \\
\hline Metastases present & 72 & . \\
\hline Metastases absent & 28 & . \\
\hline
\end{tabular}


Table 2: Comparison of the importance scores of health care professionals and patients

\begin{tabular}{|c|c|c|c|}
\hline & $\begin{array}{l}\text { Health care professionals } \\
\text { (n=60) } \\
\text { mean (SD) }\end{array}$ & $\begin{array}{c}\text { Patients } \\
(n=386) \\
\text { mean (SD) }\end{array}$ & $\begin{array}{c}\text { Profs vs Patients } \\
\text { ES\# }\end{array}$ \\
\hline \multicolumn{4}{|l|}{ Scales } \\
\hline Mistakes by professionals & $86(15)$ & $90^{1}(13)$ & \\
\hline Physician and nurse expertise & $85(13)$ & $89(11)^{*}$ & -0.35 \\
\hline Consultation and transfer & $83(15)$ & $84(14)$ & \\
\hline Physician attitude & $76(13)$ & $81(13)^{* *}$ & -0.38 \\
\hline Patient file confidentiality & $85(16)$ & $81(18)$ & \\
\hline Opportunity to choose in care and treatment & $78(13)$ & $80(14)$ & \\
\hline Nurse attitude & $80(16)$ & $78(14)$ & \\
\hline Communication and information & $78(10)$ & $77(12)$ & \\
\hline Accessibility of services & $72(13)$ & $77(14)^{* *}$ & -0.36 \\
\hline Waiting periods & $76(13)$ & $76(16)$ & \\
\hline Support, counseling and rehabilitation & $67(15)$ & $61(20)^{*}$ & +0.31 \\
\hline Alternate sources of information & $64(13)$ & $60(23)$ & \\
\hline Appointments & $62(14)$ & $59(18)$ & \\
\hline Rooms and facilities & $55(14)$ & $57(14)$ & \\
\hline Food and beverages & $56(22)$ & $56(19)$ & \\
\hline Presence of loved ones & $57(21)$ & $49(26)$ & \\
\hline Privacy & $54(18)$ & $46(22)^{*}$ & +0.37 \\
\hline Patient habits & $50(18)$ & $43(22)^{* *}$ & +0.33 \\
\hline Patient interest groups & $45(20)$ & $37(23)^{* *}$ & +0.35 \\
\hline Conveniences & $44(16)$ & $37(16)^{* *}$ & +0.44 \\
\hline Fellow-patient interaction & $19(16)$ & $17(19)$ & \\
\hline \multicolumn{4}{|l|}{ Single items } \\
\hline Hospital equipment & $66(20)$ & $84(20)^{* * *}$ & -0.90 \\
\hline Consultation at ER by own doctor & $70(23)$ & $79(20)^{* *}$ & -0.44 \\
\hline Written information & $78(20)$ & $77(21)$ & \\
\hline Support of a case manager & $69(22)$ & $74(24)$ & \\
\hline Continuity in care & $67(20)$ & $72(22)$ & \\
\hline Support by paramedical staff & $68(16)$ & $68(18)$ & \\
\hline Attention for nutrition & $63(23)$ & $68(22)$ & \\
\hline Leaving choices to doctors and nurses & $62(28)$ & $66(32)$ & \\
\hline
\end{tabular}

${ }^{1} \mathrm{~A}$ higher score indicates a higher level of importance (range 0-100);

${ }^{*} \mathrm{p}<.05,{ }^{* *} \mathrm{p}<.01,{ }^{* * *} \mathrm{p}<.001$ (Mann Whitney tests)

\# Effect size (ES) only calculated for scales and items tested as statistically significant different.

+ ES: the professionals score is higher than the patient score; - ES: the professionals score is lower than the patient score.

Generally, female health care professionals did not estimate patients' preferences and needs better than their male colleagues.

\section{Discussion}

Results of this study showed that health care professionals were able to make a correct estimation of the value cancer patients attribute to most aspects of care. In estab- lishing preferences, there was a clear similarity between patients and health care professionals. For both patients and health care professionals safety and the expertise, performance and attitude of doctors and nurses rated highest and the organisational and environmental factors were of relatively less importance. Thus, health care professionals were reasonably well able to make a correct estimation of patients' preferences. From the perspective 
Table 3: Comparison of the importance scores between female and male patients and female and male health care professionals

\begin{tabular}{|c|c|c|c|c|c|c|}
\hline & \multicolumn{3}{|c|}{$\begin{array}{l}\text { Gender } \\
\text { Patient }\end{array}$} & \multicolumn{3}{|c|}{$\begin{array}{c}\text { Gender } \\
\text { Health care professional }\end{array}$} \\
\hline & $\begin{array}{l}\text { Female } \\
(n=252)\end{array}$ & $\begin{array}{l}\text { Male } \\
(n=134)\end{array}$ & ES & $\begin{array}{l}\text { Female } \\
(n=47)\end{array}$ & $\begin{array}{c}\text { Male } \\
(n=12)\end{array}$ & ES \\
\hline \multicolumn{7}{|l|}{ Scales } \\
\hline Mistakes by professionals & $92(13)$ & $87(14)^{* *}$ & .37 & $86(14)$ & $86^{1}(17)$ & - \\
\hline Physician and nurse expertise & $90(10)$ & $88(11)$ & - & $87(12)$ & $79(13)$ & - \\
\hline Consultation and transfer & $86(13)$ & $82(14)^{*}$ & .30 & $84(14)$ & $75(18)$ & - \\
\hline Physician attitude & $83(13)$ & $78(13)^{* * *}$ & .38 & $77(12)$ & $71(16)$ & - \\
\hline Patient file confidentiality & $84(18)$ & $75(19)^{* * *}$ & .49 & $87(15)$ & $79(19)$ & - \\
\hline \multicolumn{7}{|l|}{ Opportunity to choose in care and } \\
\hline treatment & $82(14)$ & $77(15)^{* * *}$ & .35 & $78(14)$ & $77(8)$ & - \\
\hline Nurse attitude & $81(14)$ & $74(13)^{* * *}$ & .51 & $83(13)$ & $67(20)^{*}$ & 1.09 \\
\hline Communication and information & $79(11)$ & $74(13)^{* * *}$ & .43 & $79(9)$ & $74(12)$ & - \\
\hline Accessibility of services & $78(14)$ & $73(13)^{* *}$ & .37 & $72(12)$ & $72(16)$ & - \\
\hline Waiting periods & $80(14)$ & $69(18)^{* * *}$ & .71 & $78(12)$ & $69(11)^{*}$ & .76 \\
\hline Support, counseling and rehabilitation & $65(19)$ & $55(20)^{* * *}$ & .52 & $69(13)$ & $58(17)^{*}$ & .79 \\
\hline Alternate sources of information & $63(24)$ & $54(21)^{* * *}$ & .39 & $66(13)$ & $57(13)^{*}$ & .69 \\
\hline Appointments & $61(17)$ & $55(21)^{*}$ & .32 & $64(13)$ & $57(16)$ & - \\
\hline Rooms and facilities & $58(15)$ & $54(14)^{*}$ & .27 & $58(12)$ & $41(13)^{* * *}$ & 1.39 \\
\hline Food and beverages & $56(19)$ & $56(19)$ & - & $61(19)$ & $37(22)^{* * *}$ & 1.22 \\
\hline Presence of loved ones & $50(27)$ & $48(26)$ & - & $58(22)$ & $50(17)$ & - \\
\hline Privacy & $49(21)$ & $42(21)^{* *}$ & .33 & $55(20)$ & $52(11)$ & - \\
\hline Patient habits & $43(23)$ & $43(21)$ & - & $54(17)$ & $37(20)^{* *}$ & .96 \\
\hline Patient interest groups & $40(23)$ & $32(22)^{* * *}$ & .35 & $47(18)$ & $35(21)$ & - \\
\hline Conveniences & $37(17)$ & $36(16)$ & - & $47(15)$ & $32(13)^{* *}$ & 1.02 \\
\hline Fellow patient interaction & $17(19)$ & $17(20)$ & - & $19(17)$ & $20(15)$ & - \\
\hline \multicolumn{7}{|l|}{ Single items } \\
\hline Hospital equipment & $83(20)$ & $84(20)$ & - & $68(20)$ & $58(21)$ & - \\
\hline Consultation at ER by own doctor & $80(21)$ & $77(20)$ & - & $72(22)$ & $61(28)$ & - \\
\hline Written information & $80(20)$ & $73(22)^{* *}$ & .34 & $81(18)$ & $66(20)^{*}$ & .82 \\
\hline Support of a case manager & $76(23)$ & $71(25)$ & - & $71(19)$ & $64(33)$ & - \\
\hline Continuity in care & $77(20)$ & $65(23)^{* * *}$ & .57 & $68(20)$ & $66(20)$ & - \\
\hline Support by paramedical staff & $69(19)$ & $66(16)$ & - & $70(15)$ & $61(19)$ & - \\
\hline Attention for nutrition & $68(22)$ & $67(22)$ & - & $68(18)$ & $41(25)^{* * *}$ & 1.38 \\
\hline Leaving choices to doctors and nurses & $67(31)$ & $63(33)$ & - & $61(29)$ & $63(26)$ & - \\
\hline
\end{tabular}

of delivering patient centered care, these results are certainly encouraging, but there still is room for improvement. We found statistically significant differences for 8 out of 21 scales and 2 out of 8 single items. Health care professionals underestimated patients' valuation of the expertise of physicians and nurses, physician attitude, the accessibility of services, a modern hospital equipment and the possibility to be seen by the own doctor directly 
in case of an emergency. On the other hand, health care professionals overestimated the value that patients set on particularly organisational and environmental aspects.

These findings may be of interest to improve care for cancer patients. Our finding suggest that health care professionals may focus too much on aspects of care that patients attach less value to and may pay less attention to aspects that are in the opinion of the patient most important. Failure to tailor care as much as possible to patients' needs and preferences may lead to (unnecessary) dissatisfaction and distress among patients. Patients with unmet needs in the terminal stage of cancer for example, show significantly higher psychological and symptom distress [28].

Prioritization of care aspects by patients is a valid starting point in care renewal processes and may be used to guide decisions in improving care for cancer patients. However, in reorganizing care, the knowledge and experience of health care professionals and logistical and financial constraints should also be taken into account.

Our study also showed that - similar to patients female health care professionals set higher value on many care aspects than male professionals do. However, in general female health care professionals did not make better estimates of patients' preferences than their male counterparts.

To deliver patient centered care and thereby effectively meet patients needs and wishes, health care professionals should take into account context characteristics of individual patients and customize their services as much as possible. The literature shows that patient characteristics impact upon patients experiences and preferences in health care [21,29-32]. In interpreting the results of this study it is important to be aware of the fact that individual patient characteristics were not taken into account by health care professionals while estimating patient preferences in the questionnaire. The results of the study among patients is an average of 386 respondents and we asked health care professionals to fill out the questionnaire for the average cancer patient. In improving cancer care at the organisational level, health care professionals generally use the average patient as starting point, but standardised care does not meet the need of the individual patient. Further research should therefore focus on the estimation of patient preferences by health care professionals for specific patients or groups of cancer patients (paying attention to the influence of, for example, gender, age, level of education, phase of illness).

There are some limitations of this study. A possible limitation concerning the representativeness of our sample of patients participating in the focus group interviews is the overrepresentation of young patients. It is possible that age may be a confounder in the items addressed. Other potential limitations of this study are the relatively small number of participating health care professionals compared to the number of patients, the (unexplained) low response rate of health care professionals and the relative overrepresentation of nurses and female health care professionals, due to the fact that there are many more nurses working at the departments of medical oncology than physicians and policymakers. Therefore, in future research it is important to expand and confirm these findings in a larger population of health care professionals, including a larger proportion of physicians and policymakers.

\section{Conclusions}

In conclusion, this study showed that health care professionals are reasonably well able to make a correct estimation of cancer patients preferences in general. Nevertheless there are some blind spots. Health care professionals both underestimate and overestimate the value patients attach to a number of care aspects. They should be aware of their own bias and use additional resources to make it possible to optimally differentiate towards patient specific preferences for each patient is different and ultimately the care needs and preferences will also be unique to the person. This indicates the need to develop interventions aimed at supporting professionals in gaining a better insight and understanding of patients' specific preferences, to be fully informed on the patients' preference pattern and thereby to ensure that health care truly meets patients preferences. Furthermore, patients should be encouraged and supported to supply the necessary information for health care professionals to get insight into their specific needs and preferences concerning cancer care.Tailoring care for cancer patients should be a multidisciplinary action of health care professionals and patients to avoid potential biases in perceived needs and preferences of these patients.

\section{Competing interests}

The authors declare that they have no competing interests.

\section{Authors' contributions}

HW: Conception and design, administrative support, provision of study material or patients, collection and assembly of data, data analysis and interpretation and manuscript writing. AdG: Conception and design, provision of study material or patients, data analysis and interpretation and manuscript writing. KW: Conception and design, data analysis and interpretation and manuscript writing. MdH: Administrative support, provision of study material or patients, collection and/or assembly of data, data analysis and interpretation. CK: Data analysis and interpretation and manuscript writing. ST: Provision of study material or patients and manuscript writing. EV: Conception and design, provision of study material or patients, data analysis and interpretation and manuscript writing. All authors read and approved the final manuscript

\section{Acknowledgements}

We gratefully thank the cancer patients who were kind enough to share personal information and ideas about a desirable care and treatment and who spent time filling out our questionnaire. We also thank the health care professionals who were kind enough to distribute questionnaires to the patients and spent time filling out our questionnaire. We also wish to thank Annelies Hetharia MSC (UMC Utrecht), Else Mulder MCC (UMC Utrecht), Rachel Giles PhD (UMC 
Utrecht), Mirjam Majoor MSc (NFK) and Gerda Woltjer and Margriet van der Heiden MSc (IKMN) for their valuable contribution and support.

This study was supported by grants from the Health Insurers Innovation Foundation (dossier 894) and the Comprehensive Cancer Center Middle Netherlands (dossier 2005/01)

\section{Author Details}

'Department of Corporate Communications, University Medical Center Utrecht, Heidelberglaan 100, 3508 GA, Utrecht, The Netherlands, 2Department of Medical Oncology, University Medical Center Utrecht, Heidelberglaan 100, 3508 GA, Utrecht, The Netherlands, ${ }^{3}$ Graduate School for Health Research (SHARE), University Medical Center Groningen, Hanzeplein 1, 9700 RB, Groningen, The Netherlands and 4 Julius Center for Health Sciences and Primary Care, University Medical Center Utrecht, Heidelberglaan 100, 3508 GA, Utrecht, The Netherlands

Received: 11 March 2010 Accepted: 8 July 2010

Published: 8 July 2010

\section{References}

1. Donabedian A: The Quality of Care - How Can It be Assessed. JamaJournal of the American Medical Association 1988, 260(12):1743-1748.

2. Institute of Medicine Committee on Quality of Health Care in America: Crossing the Quality Chasm: A New Health System for the $21^{\text {st }}$ Century. 2001. Washington DC, National Academy Press; 2001:1-337. Ref Type: Report

3. Wessels H, de Graeff A, Wynia K, Sixma HJ, Heus de, Schipper M, Woltjer TGJ, Teunissen SCCM, Voest EE: Medical oncology patients' preferences with regard to health care: development of a patient-driven questionnaire. Ann Oncol 2009, 20:1708-1713.

4. Tamburini M, Gangeri L, Brunelli C, Boeri P, Borreani C, Bosisio M, Bosisio M, Karmann CF, Greco M, Miccinesi G, Murru L, Trimigno P: Cancer patients' needs during hospitalisation: a quantitative and qualitative study. BMC Cancer 2003:12.

5. Skarstein J, Dahl AA, Laading J, Fossa SD: 'Patient satisfaction' in hospitalized cancer patients. Acta Oncol 2002, 41(7-8):639-645.

6. Wiggers JH, Donovan KO, Redman S, Sanson-Fisher RW: Cancer patient satisfaction with care. Cancer 1990, 66(3):610-616.

7. Turhal NS, Efe B, Gumus M, Aliustaoglu M, Karamanoglu A, Sengoz M: Patient satisfaction in the outpatients' chemotherapy unit of Marmara University, Istanbul, Turkey: a staff survey. BMC Cancer 2002, 2:30.

8. Kleeberg UR, Tews JT, Ruprecht T, Hoing M, Kuhlmann A, Runge C: Patient satisfaction and quality of life in cancer outpatients: results of the PASQOC* study. Supp Care Cancer 2005, 13:303-310

9. Gourdji I, McVey L, Loiselle C: Patients' satisfaction and importance ratings of quality in an outpatient oncology center. J Nurs Care Qual 2003, 18:43-55.

10. Sandoval GA, Brown AD, Sullivan T, Green E: Factors that influence cancer patients' overall perceptions of the quality of care. Int J Quality Health Care 2006, 18:266-274.

11. Sandoval GA, Levinton C, Blackstien-Hirsch P, Brown AD: Selecting predictors of cancer patients' overall perceptions of the quality of care received. Ann Oncol 2006, 17:151-156.

12. Gesell SB, Gregory N: Identifying priority actions for improving patient satisfaction with outpatient cancer care. I Nurs Care Qual 2004, 19:226-233.

13. Bredart A, Razavi D, Delvaux N, Goodman V, Farvacques C, van Heer C: A comprehensive assessment of satisfaction with care for cancer patients. Supp Care Cancer 1998, 6:518-523.

14. de Kok M, Scholte RW, Sixma HJ, van der Weijden T, Spijkers KF, van der Velde CJH, Roukema JA, van der Ent FW, Bell AVRJ, von Meyenfeldt von MF: The patient's perspective of the quality of breast cancer care--the development of an instrument to measure quality of care through focus groups and concept mapping with breast cancer patients. Eur $J$ Cancer 2007, 43:1257-1264.

15. Mulders M, Vingerhoets A, Breed W: The impact of cancer and chemotherapy: Perceptual similarities and differences between cancer patients, nurses and physicians. Eur J Oncol Nurs 2008, 12:97-102.

16. Lampic C, Sjödén PO: Patient and staff perceptions of cancer patients' psychological concerns and needs. Acta Oncologica 2000, 39:9-22.
17. Mårtensson G, Carlsson M, Lampic C: Are cancer patients whose problems are overestimated by nurses less satisfied with their care? Eur $J$ Cancer Care 2009 in press.

18. Newell S, Sanson-Fisher RW, Girgis A, Bonaventura A: How well do medical oncologists' perceptions reflect their patients' reported physical and psychosocial problems? Cancer 1998, 83:1640-1651.

19. Sharpe L, Butow P, Smith C, Mc Connell D, Clarke S: The relationship between available support, unmet needs and caregiver burden in patients with advanced cancer and their carers. Psychooncology 2005, 14:102-114

20. Brennan PF, Strombom I: Improving health care by understanding Patient Preferences: the role of computer technology. J Am Med Inform Assoc 1998, 5(3):257-262.

21. Wessels H, de Graeff A, Wynia K, de Heus M, Kruitwagen CLJ, Woltjer TGJ, Teunissen SCCM, Voest EE: Gender-related needs and preferences in cancer care indicate the need for an individualized approach to cancer patients. The Oncologist 2010 in press.

22. Van den Brink-Muinen A, Bensing JM, Kerssens JJ: Gender and Communication Style in General Practice: Differences Between Women's Health care and Regular Health Care. Med Care 1998, 36(1):100-106.

23. Bensing JM, van den Brink-Muinen A, de Bakker DH: Gender differences in practice style: a Dutch study of general practitioners. Med Care 1993, 31:219-29.

24. Weisman CS, Teitelbaum MA: Physician gender and the physicianpatient relationship: recent evidence and relevant questions. Soc Sci Med 1985, 20:1119.

25. US department of Health and Human Services Office on Women's Health: Literature review on effective sex- and gender-based systems/models of care, the Office on Women's health. 2007. Ref Type: Report

26. Cohen J: Statistical power analysis for the behavioral sciences. second edition. New York: Academic Press; 1988.

27. Middel B, Stewart R, Bouma J, van Sonderen E, van den Heuvel WJA: How to validate clinically important change in health-related functional status. Is the magnitude of the effect size consistently related to magnitude of change as indicated by a global question rating? J Eval Clin Pract 2001, 7(4):399-410,

28. Morasso G, Capelli M, Viterbori P, Di Leo S, Alberisio A, Costantini M, Fiore M, Saccani D, Zeitler G, Verzolatto N, Tirelli W, Lazzari L, Partinico M, Borzoni G, Savian C, Obertino E, Zotti P, Ivaldi GP, Henriquet F: Psychological and Symptom distress in terminal cancer patients with met and unmet needs. J Pain Symptom manage 1999, 17(6):402-409.

29. Nguyen Thi PL, Briancon S, Empereur F, Guillemin F: Factors determining inpatient satisfaction with care. Soc SciMed 2002, 54:493-504.

30. Hargraves JL, Wilson IB, Zaslavsky A, James C, Walker JD, Rogers G, Clery PD: Adjusting for patient characteristics when analyzing reports from patients about hospital care. Med Care 2001, 39(6):635-641.

31. Quintana JM, Gonzalez N, Bilbao A, Aizpuru F, Escobar A, Esteban C, SanSebastian JA, De-la-Sierra E, Thompson A: Predictors of patient satisfaction with hospital health care. BMC health services research 2006, 6:102.

32. Rosén $P$, Anell A, Hjortsberg C: Patient views on choice and participation in primary health care. Health Policy 2001, 55:121-128.

\section{Pre-publication history}

The pre-publication history for this paper can be accessed here: http://www.biomedcentral.com/1472-6963/10/198/prepub

doi: 10.1186/1472-6963-10-198

Cite this article as: Wessels et al., Are health care professionals able to judge cancer patients' health care preferences correctly? A cross-sectional study BMC Health Services Research 2010, 10:198 